\title{
Hydrogen-terminated Detonation Nanodiamond: Impedance Spectroscopy and Thermal Stability Studies
}

Author List:

\section{Shi Su}

Affiliation: Nanoscience Research Group, Department of Electrical, Electronic and Power Engineering, School of Engineering and Applied Science, Aston University

Email:sus1@aston.ac.uk

\section{Jiangling Li}

Affiliation: Nanoscience Research Group, Department of Electrical, Electronic and Power Engineering, School of Engineering and Applied Science, Aston University

Email: lij23@aston.ac.uk

\section{Vojtěch Kundrát}

Affiliation: Nanoscience Research Group, Department of Electrical, Electronic and Power Engineering, School of Engineering and Applied Science, Aston University

Email: kundratv@aston.ac.uk

\section{Andrew M. Abbot}

Affiliation: Nanoscience Research Group, Department of Electrical, Electronic and Power Engineering, School of Engineering and Applied Science, Aston University

Email: a.m.abbot@aston.ac.uk

\section{Haitao Ye (Corresponding Author)}

Affiliation: Senior Lecturer of Nanoscience Research Group, Department of Electrical, Electronic and Power Engineering, School of Engineering and Applied Science, Aston University

Email: h.ye@aston.ac.uk 


\title{
Hydrogen-terminated Detonation Nanodiamond: Impedance Spectroscopy and Thermal Stability Studies
}

\author{
Shi Su, Jiangling Li, Vojtěch Kundrát, Andrew M. Abbot and Haitao Ye ${ }^{\text {a) }}$ \\ School of Engineering and Applied Science, Aston University, Birmingham, United \\ Kingdom, B4 7ET
}

\begin{abstract}
In this paper, we investigated the effect of hydrogen termination on the electrical properties and impedance spectra of detonation nanodiamond. The impedance spectra revealed that the hydrogen-termination process increases the electrical conductivity by four orders of magnitude at room temperature. An equivalent circuit has been proposed to correlate with the conduction mechanism. Arrhenius plot showed that there were two different activation energy levels located at $0.089 \mathrm{eV}$ and $0.63 \mathrm{eV}$ between $50^{\circ} \mathrm{C}$ and $400^{\circ} \mathrm{C}$. The possible physical mechanism corresponding to these activation energy levels has been discussed. Hydrogen-terminated detonation nanodiamond has been further annealed at different temperatures prior to FTIR and XPS measurements in order to understand their thermal stability. The results demonstrated that the surface oxidization occurred between $100^{\circ} \mathrm{C}$ and $150^{\circ} \mathrm{C}$. However, the $\mathrm{C}-\mathrm{H}$ bonds could partially survive when the temperature reaches $400^{\circ} \mathrm{C}$ in air. (C) 2012 American Institute of Physics.
\end{abstract}

\footnotetext{
a) Author to whom correspondence should be addressed; electronic mail: h.ye@aston.ac.uk
} 


\section{INTRODUCTION}

Detonation-synthesized nanodiamond (DND) is an attractive class of diamond material, which has great potential to be used for a wide range of applications. DND powder has been widely used as a biocompatible material for in-vivo drug delivery carriers, ${ }^{1}$ electrochemical catalysts, ${ }^{2}$ fluorescent biomedical markers, ${ }^{3}$ purification of proteins, ${ }^{4}$ and bacterial binding biosensors, ${ }^{5}$ et al. More recently, our research has found that nanodiamond additives can help loosen crystallized fat from surfaces at low temperature, which transforms the ability of washing powders to remove dirt in eco-friendly low temperature laundry cycles. ${ }^{6}$ This will have the potential to bring huge energy savings in an essential, everyday domestic wash. Understanding the surface properties of DND powders and the ability to manipulate the surface physical and chemical properties of DND particles are crucial for specific applications discussed above.

Each individual DND particle has a "sootlike" structure outside the core, which is composed of free graphitic layers (or other $s p^{2} / s p^{3}$ non-diamond species), metallic residues, the balance oxygen being and explosives from the detonation process. ${ }^{7}$ Hydrogen- and oxygen-termination processes are common methods for functionalizing the DND's surface. It is well established that hydrogen-termination of two-dimensional (2D) diamond thin films can lead to p-type electrical conduction and hydrophobic surfaces, whilst the oxygen termination will form hydrophilic surfaces. ${ }^{8}$ Since the DND has an average grain size in the nano-meter range, the hydrogen termination on the surfaces of DND particles might present some different properties when compared with 2D thin films. Therefore studies of DND deaggregation, modification, surface characterization and thermal stability have attracted significant interest from research community. Early reports of FTIR, NMR and XRD of DND particles revealed that the surface structures contained various non-diamond species (e.g. C-C, 
$\mathrm{C}=\mathrm{C}, \mathrm{C}-\mathrm{H}_{\mathrm{x}}, \mathrm{C}-\mathrm{O}, \mathrm{C}=\mathrm{O}$ ) as well as other functional groups. ${ }^{9}$ Yeganeh and Zeppilli et al. studied thermal annealing effect using photoemission spectroscopy (PES) and XPS. ${ }^{10,11}$ Xie et al. investigated the graphitization of nanodiamond surface. ${ }^{12}$ Jackman's team has reported the impedance spectroscopy (IS) data on both aggregated DNDs in the as-received condition and monodispersed DNDs. ${ }^{13,14}$ However, the electrical properties of surface-modified DNDs have not been specifically investigated due to the difficulties in measurements and instrumentation. We have recently designed a novel testing system for impedance measurement of particles and powders. ${ }^{15}$ This testing system will be used here to collect more accurate data and to characterize the electrical properties of DNDs.

In this paper, untreated DND samples and hydrogen-terminated DND (H-DND) samples were used to perform spectroscopic impedance studies. In order to understand the thermal stability of these samples, annealing treatment has been carried out on H-DND at different heating temperatures ranging from $50^{\circ} \mathrm{C}$ to $400^{\circ} \mathrm{C}$. FTIR and XPS results on these annealed samples have provided an insight into the evolution of the physical and chemical properties of the H-DND.

\section{EXPERIMENTAL METHEDOLOGY}

‘As-received’ state DND powders (SIGMA-Aldrich Corp., average grain size: 4 6 nm) have been used throughout this study. A scanning electron microscopy image of a typical particle is shown in Fig 1. It can be seen that extremely small nanometer-scale crystals aggregated and form grain size of 50-150 nm, which in turn make up the $\sim 2 \mu$ m particles.

The H-termination process was carried out using ASTeX5010 (Seki Technotron Corp., 2.45 GHz, $1.5 \mathrm{~kW}$ ) microwave plasma enhanced chemical vapor deposition (MPECVD) system. A custom-designed molybdenum holder was placed inside the chamber to constrain the DND powders during the plasma process. The optimized microwave power was $900 \mathrm{~W}$ at 
a pressure of 50 Torr with a hydrogen gas flow rate of 200 s.c.c.m. The duration of Htermination treatment was fixed for 10 minutes and the temperature was set at $850^{\circ} \mathrm{C}$, which was recorded by an infrared thermometer (model: Williamson Pro 92-40-C, range: 475$\left.1475^{\circ} \mathrm{C}\right)$. At the end of the plasma process, the samples were maintained inside the chamber until cooled to room temperature. After cooling, DND samples were removed and a fixed amount of the DND samples were loaded into the testing cell for measurement.

It is impractical to carry out the IS measurement on a single particle, hence a customdesigned measurement system for IS on DND powder has been introduced as shown in Fig. 2. The testing cell includes two copper plates, one of which has been carefully polished and then electroplated with high-purity nickel, which served as the bottom electrode. A hollow ceramic washer has been attached to the copper plate with high-temperature silver paste. Heating to $150^{\circ} \mathrm{C}$ in air cures the paste thus ensuring the washer has been tightly attached onto the bottom electrode, which serves as the sample container. A stainless steel bolt serves as the top electrode and another smaller copper plate holds the top electrode with two ceramic screws, which have been fixed onto the copper plate. The ceramic washer and the screws isolate the top electrode electrically from the lower one. Two metal springs have been fitted between the top and bottom copper plates to provide a relative constant force to the DND powders. This pressure generated from these springs is particularly important in measuring the porous materials/powders as the force resulted from the springs will influence the porosity/density of DND and consequently impact on the electrical response. ${ }^{15}$ The overall temperature error during the measurement is $\pm 2^{\circ} \mathrm{C}$.

The IS impedance measurement was carried out in air at elevated temperatures from $50^{\circ} \mathrm{C}$ to $400^{\circ} \mathrm{C}$ using an Autolab PGSTAT 302N electrochemical system (Windsor Scientific Ltd) connected to the testing cell. The temperature range was limited to a maximum of $400^{\circ} \mathrm{C}$, as the DND particles experience a catastrophic weight loss at temperatures above $400^{\circ} \mathrm{C} \cdot .^{14,16}$ 
The IS was performed over a frequency ranging from $0.1 \mathrm{~Hz}$ to $10 \mathrm{MHz}$ with a potential bias of $0.35 \mathrm{~V}$.

ESCALAB 250 X-ray Photoelectron Spectrometer (Thermo Corp.) with monochromatized $\mathrm{Al} \mathrm{K \alpha}(1486.5 \mathrm{eV}) \mathrm{X}$-ray source was employed to analyze the surface bonding states of the DND powders with a base pressure of $5 \times 10^{-10}$ mbar in the analysis chamber and a pass energy of $20 \mathrm{eV}$. The DND powders were attached on the stage by a double-sided conductive carbon paste. The infrared spectra were collected from Thermo IR 200 FTIR Spectrometer using $\mathrm{KBr}$ pellets. The $\mathrm{KBr}$ pellets were prepared by mixing a $25 \mathrm{mg}$ DND sample with 250 mg potassium bromide (SIGMA-Aldrich Corp.). The pellets were pressed and placed into a desiccator with silica gel to remove the absorbed water on them. For FTIR and XPS measurements, all the H-DND samples were annealed in air at different temperatures from $50^{\circ} \mathrm{C}$ to $400^{\circ} \mathrm{C}$.

\section{RESULTS AND ANALYSIS}

\section{A. Impedance spectroscopy}

Impedance spectroscopy (IS) is a powerful tool for investigating the electric and dielectric behavior of ionic, electronic or mixed conductor ceramic. ${ }^{17}$ It has been successfully applied in characterizing the electrical properties of grain interiors as well as the grain boundaries properties of polycrystalline, nanocrystalline diamond, $\delta$-doped diamond and mono-layer nanodiamond. ${ }^{14,18-21}$ In essence, the IS technique involves the measurement of real and imaginary parts of the complex impedance as a function of frequency. The impedance can be expressed as a complex value as

$$
\begin{aligned}
& Z(\omega)=Z^{\prime}+j Z^{\prime \prime} \\
& Z^{\prime}=\sum_{i=1}^{\pi} \frac{\kappa_{l}^{\prime}}{2+\omega^{2}{ }^{\prime} c_{i}^{\prime} c_{i}^{\prime}}
\end{aligned}
$$




$$
Z^{\prime \prime}=\sum_{i=1}^{12} \frac{\omega N_{i}^{2} c_{i}}{1+\omega^{2} K_{i}^{2} c_{i}^{2}}
$$

where $Z(\omega)$ is the complex ac impedance as a function of angular frequency; $\omega$ is angular frequency; $Z$ ' is the real part of impedance, referring to the resistive contribution from the measured impedance; and $Z "$ is the imaginary part of impedance, representing the capacitive contribution. The variable $n$ can take values between 1 and 3 , corresponding to the different types of conduction path. The real part of impedance versus the imaginary part can be plotted in one figure as a function of frequency, which forms a so-called Cole-Cole plot. The ColeCole plot can be fitted with an equivalent circuit from which the conduction mechanism can be deduced. $^{18-20}$

Impedance spectroscopy results of untreated DND samples and H-DND samples are shown in Fig. 3. Each measurement was taken by using the same amount of nanodiamond and presented in the format of Cole-Cole plot. The Cole-Cole plot of untreated nanodiamond is shown in Fig. 3 (a), which exhibits a near-perfect semicircle. The diameter of the fitted semicircle that is intercepted on the $Z$ ' axis indicates the real part of the impedance, i.e. resistance. The single semicircle indicates that only one primary mechanism exists for the conduction within the untreated DND sample. In order to analyze the impedance data further, a single resistor-capacitor (RC) parallel $\left(R_{\mathrm{p}} / / C_{\mathrm{p}}\right)$ equivalent circuit can be used to simulate the electrical properties of untreated DNDs as shown in Fig. 4 (a). The fitting procedure used here is the same as the one described by Kleitz et $a .^{22}$ Here, the RC parallel circuit can be used to characterize the impedance contributed from the stacked particles. The resistance $\left(R_{\mathrm{p}}\right)$ of the sample was calculated around $7 \times 10^{9} \Omega$ by fitting the arc with this equivalent circuit.

The Cole-Cole plot of H-DND sample at room temperature is shown on Fig. 3 (b), which consists of a semicircle at higher frequencies and a straight line at low frequencies. The diameter of the fitted semicircle that is intercepted on the $Z^{\prime}$ axis, indicates the resistance of H-DND sample is around $2.46 \times 10^{5} \Omega$, which is four orders of magnitude less than untreated 
DND samples. Note that the low-frequency spectra of H-terminated DND forms a straight line at a $45^{\circ}$ angle to both $Z^{\prime}$ and $Z^{\prime \prime}$ axis. This phenomenon suggests that the corresponding equivalent circuit may consist of a Warburg diffusion component (see Fig. 4 (b)). ${ }^{23}$ The complex Warburg impedance $Z_{\mathrm{w}}$ is composed by a constant phase element (CPE), which can be expressed as:

$$
Z_{C Y_{i}}=Z(j \omega)^{-\sigma}=Z(\omega)^{-\pi}\left[\cos \left(-\sigma \cdot \frac{\pi}{2}\right)+j \cdot \sin \left(-\sigma \cdot \frac{\pi}{2}\right)\right]
$$

where $Z$ represents the impedance in Eq. (1) and $\omega$ is the angular frequency. The exponent $\sigma$ is a frequency-dependent correction factor with the value between 0 and 1 . When $\sigma$ is 1 , the CPE component is a pure capacitor and 0 for a pure resistor. As the exponent $\sigma$ equals to $1 / 2$, Eq. (4) can be expressed as:

$$
Z_{t w}=\left(\frac{w}{w}\right)(1-j)
$$

which was described as Warburg diffusion element. The Warburg diffusion element can be used to characterize infinite-length approximation of DND particles stacked together and mutual interaction after hydrogen passivation process. Preliminary analysis suggests that the presence of the Warburg element can be attributed to the water absorption on the surface and the colloidal properties of the DND powder. ${ }^{24}$ Besides, the formation of C-H bonds on DND particles' shell enhances their conductivity and possibly enables an infinite-length approximation of their electrical properties. Similar results have been reported on the electrochemical properties of DND fabricated electrodes by Zang et al. ${ }^{25}$ The author attributed the low frequency linear portion to the inhomogeneous porous structure, which leads to a non-ideal capacitive element.

When the measurement temperature increases to $50^{\circ} \mathrm{C}$, the impedance data of H-DND samples show a similar trend as those measured at room temperature (Fig. 3 (c)). The resistance is increased to $\sim 5.2 \mathrm{M} \Omega$ (at $50^{\circ} \mathrm{C}$ ). Fig 3. (d) shows the impedance spectra of $\mathrm{H}$ DND at $100^{\circ} \mathrm{C}$. At this temperature, the Warburg effect has become negligible and overall 
resistance has increased with increasing temperature. This observed phenomenon could be explained by the fact that the absorbed water evaporates from the DND particles surface when the samples being heated up to $100^{\circ} \mathrm{C}$ in air. ${ }^{25,26}$ Impedance spectra of H-DND samples at $150^{\circ} \mathrm{C}, 200^{\circ} \mathrm{C}$ and $250^{\circ} \mathrm{C}$ are shown in Fig. 3 (d) and (e). In these figures, the Warburg effect completely disappears at these temperatures. $R_{\mathrm{p}}$ increased to $0.15 \mathrm{G} \Omega, 1.84 \mathrm{G} \Omega$ and $2.22 \mathrm{G} \Omega$ at temperature measured at $150^{\circ} \mathrm{C}, 200^{\circ} \mathrm{C}$ and $250^{\circ} \mathrm{C}$, respectively. At $250^{\circ} \mathrm{C}$, the sample showed a maximum resistance value, which is four orders magnitude higher than the H-DND sample measured at room temperature. The increase in the resistance at the temperature range from $150^{\circ} \mathrm{C}$ to $250^{\circ} \mathrm{C}$ could be explained as the incorporation of oxygen onto the surface of the DND powders. Further evidence will be provided via XPS and FTIR measurements in Sec. III. With temperature increasing to $300^{\circ} \mathrm{C}$ and to $350^{\circ} \mathrm{C}$, the semicircle starts to shrink. The resistance decreases from $2.22 \mathrm{G} \Omega$ at $250^{\circ} \mathrm{C}$ to $0.834 \mathrm{G} \Omega$ and $0.246 \mathrm{G} \Omega$, respectively. The drop in the resistance is probably due to thermal activation of non- diamond phase impurities on the DND particles and will be discussed in Sec. IV. A. Finally, when temperature increases to $400^{\circ} \mathrm{C}$, the resistance increases again to $\sim 0.8 \mathrm{G} \Omega$, as shown in Fig. 3 (f). It is likely to be due to the oxidation of DND surfaces. ${ }^{27}$ At this temperature, the Warburg effect appeared again as it was in low-frequency range, which suggested to be associated with an increase in the surface homogeneity on the DND particles. ${ }^{28}$ The resistance error results from the following two factors: Autolab equipment system error $( \pm 0.2 \%)$ and numerical fitting error $( \pm 5 \%)$.

\section{B. Arrhenius relationship}

In Fig. 5, the Arrhenius relationship was plotted by $R_{\mathrm{p}}$ versus $1000 / \mathrm{T}$ at temperatures ranging from room temperature to $400^{\circ} \mathrm{C}$. First of all, the resistance $R_{\mathrm{p}}$ increases with the increasing temperature up to $150^{\circ} \mathrm{C}$. At this stage, the primary electrical conduction 
mechanism is attributed to the surface absorbed water, which provides a conduction path between the aggregated nanodiamond particles. ${ }^{13,14}$ Secondly, for the temperatures ranging from $170^{\circ} \mathrm{C}$ to $225^{\circ} \mathrm{C}$, the resistance $R_{\mathrm{p}}$ decreases with increasing temperature. The Arrhenius relationship can be expressed by Eq. (6) and (7):

$$
\begin{aligned}
& R=A c^{-\frac{E_{\text {act }}}{K T}}
\end{aligned}
$$

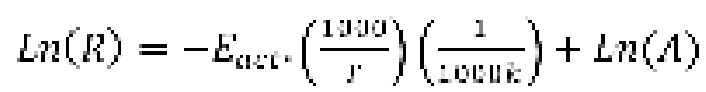

where $E_{\text {act }}$ represents the activation energy of a certain kind of semiconductor and $k$ is the Boltzmann's constant. From Eq. (5), an activation energy of $E_{\mathrm{act} 1}=0.089 \mathrm{eV}$ can be calculated covering the data between $170^{\circ} \mathrm{C}$ to $225^{\circ} \mathrm{C}$, which could be associated with the thermal activation from the hydrogen-termination on H-DND. Finally, for the temperatures ranging from $250^{\circ} \mathrm{C}$ to $350^{\circ} \mathrm{C}$, the resistance $R_{\mathrm{p}}$ decreases with increasing temperature. From Eq. (7), an activation energy of $0.63 \mathrm{eV}$ can be allocated to these data. Detailed discussion will be given in Sec. 4 A.

\section{FTIR spectroscopy}

In order to understand the thermal stability of the nanodiamond powder, we have carried out thermal annealing experiments on H-DND, at temperatures ranging from $50^{\circ} \mathrm{C}$ to $400^{\circ} \mathrm{C}$. Fig. 6. Shows the FTIR results of untreated DND samples, and H-DND samples with post annealing. All the FTIR spectrum displayed a significant peak located at $1630 \mathrm{~cm}^{-1}\left(\delta_{\mathrm{OH}}\right.$ bend mode), which were derived from the absorbed water on the surface. ${ }^{29,30}$ For the untreated DND powder spectra, one low intensity peak located at $619 \mathrm{~cm}^{-1}$ was observed and disappeared after H-termination. This peak should be associated with the carbon amide bonds on the particles' surface and it did not appear during the thermal treatment in air. ${ }^{9}$ The peak around $1126 \mathrm{~cm}^{-1}$ in untreated sample might be assigned as either the ether group ( $v_{\mathrm{C}-\mathrm{O}-\mathrm{C}}$ ) or the $\delta_{\mathrm{OH}}$ vibration from water. Here, it is more likely to be associated with the water absorbed 
on the surface of the DND powder rather than the ether group. Thus the surface chemical properties (such as hydrophilic or hydrophobic) would have an influence on the intensity of this peak. This peak at $1126 \mathrm{~cm}^{-1}$ became weakened after the H-termination, which could be explained by the fact that H-termination enhances the hydrophobic properties of the DND particles through the formation of $\mathrm{C}-\mathrm{H}$ bonds on the surface. ${ }^{31}$ The peak around $1255 \mathrm{~cm}^{-1}$, which is linked with the C-O group, was not significant for the untreated sample but became dominant when the annealing temperature reached $150^{\circ} \mathrm{C}$ or above. This result suggests that the H-DND particles' surface starts to oxidize in air at $150^{\circ} \mathrm{C}$. The weak peak located at 1336 $\mathrm{cm}^{-1}$ proved the existence of the $\mathrm{C}-\mathrm{N}$ bonds (cyclic carbon in cyclic lactams, $\left.-\mathrm{C}=\mathrm{NH}\right){ }^{9}$ This peak survived after H-termination treatment and then started broadening with the increasing annealing temperature. Eventually, it vanished at the $350^{\circ} \mathrm{C}$ or above. The peak located at $1731 \mathrm{~cm}^{-1}$ is due to the presence of the $\mathrm{C}=\mathrm{O}$ bonds (carbonyl group), which was associated with ester or amide. This peak was observed in the untreated DND sample but disappeared after hydrogen plasma treatment. After annealing at $300^{\circ} \mathrm{C}$ or above, the peak at $1731 \mathrm{~cm}^{-1}$ reappeared which implied that the formation of the $\mathrm{C}=\mathrm{O}$ bonds. After hydrogen plasma passivation, the H-DND exhibited surface modification with two broad peaks located at 2930 and $2960 \mathrm{~cm}^{-1}$, while the untreated sample did not. These two absorbance peaks correspond

to alkyl $s p^{3} \mathrm{C}-\mathrm{H}\left(-\mathrm{CH}_{3} /-\mathrm{CH}_{2}\right)$ bonds stretching vibration mode. ${ }^{9}$ Summarizing the FTIR results from untreated and H-DND samples, it can be concluded that the hydrogentermination process functionalizes the surface of DND with $\mathrm{C}-\mathrm{H}$ bonds and removes a certain percentage of carbon-oxygen compounds.

\section{X-ray Photoelectron Spectroscopy}

XPS technique has been applied to determine the relative composition of the DND samples. Survey spectra have been recorded for all the samples (untreated DND, H-DND, 
and the thermally annealed H-DND powders) and subsequent curve fitting is shown in Fig.7. The significant C1s peaks between 280.0 and $290.0 \mathrm{eV}$ have been normalized in order to highlight the other impurity peaks. The minimal chromium impurities ( $\mathrm{Cr} 2 p 1 / 2 p 3$ : 584.7/575.7 eV) can be derived from the post-synthesis using a $\mathrm{Cr}_{2} \mathrm{O}_{3} / \mathrm{H}_{2} \mathrm{SO}_{4}$ mixture to oxidize $s p^{2}$ carbon element. ${ }^{32}$ From the XPS analysis, there is no evidence that other metallic impurities are presented in the DND sample, which indicates the as-received samples should have been purified with acids mixture (e.g. hydrochloric acid/nitric acid mixture). ${ }^{33,34}$ The O1s line in the survey spectrum is located at $529.4 \mathrm{eV}$, which can be associated with the surface ether, hydroxyl and carbonyl bonds. ${ }^{35}$ The N1s spectrum includes two components with maximum at $400.8 \mathrm{eV}$ and $397.8 \mathrm{eV}$. The $\mathrm{N} 1 \mathrm{~s}$ located at $400.8 \mathrm{eV}$ is the evidence of interaction with oxygen and the other one represents nitrogen atoms incorporated in the nanodiamond core. ${ }^{36}$ For the untreated DND sample, impurities such as oxygen and nitrogen can be attributed to the reaction involving the detonation process, which contains oxygendeficient trinitrotoluene (TNT) and hexogen composition. ${ }^{37}$ After hydrogen termination, the oxygen peak has significantly decreased, while the nitrogen and chromium peaks remain as before. The ratio of each composition on DND analyzed by XPS was listed in Table 2. The content of chromium for each sample was constant before/after H-termination treatment and during the annealing process. After hydrogen passivation, the oxygen concentration significantly decreased. ${ }^{14}$ When the annealing temperature reached $150^{\circ} \mathrm{C}$ or above, the oxygen percentage increased. Meanwhile, the nitrogen concentration slightly increased with increasing temperature from $50^{\circ} \mathrm{C}$ to $350^{\circ} \mathrm{C}$. A detailed analysis has been discussed in Section IV.

\section{DISCUSSION}


According to Eq. (3), when $n=3$, this equation indicates that there are three conduction mechanisms in the semiconductor material namely: electrode, grain interiors (GI) and grain boundaries (GB). ${ }^{17-19}$ It was already established in literature that the capacitance associated with grain boundary $\left(C_{\mathrm{GB}}\right)$ is 2-3 orders of magnitude higher than the capacitance associated with the grain interior $\left(C_{\mathrm{GI}}\right){ }^{19,22}$ The parameters $R_{\mathrm{p}}$ and $C_{\mathrm{p}}$ were extracted from the fitting equivalent circuit and shown in Table 1 . The paralleled resistance $R_{\mathrm{p}}$ and capacitance $C_{\mathrm{p}}$ represent the intrinsic resistivity and the dielectric properties of the H-DND. $R_{\mathrm{p}}$ varied with the increasing temperature but the parallel capacitance $C_{\mathrm{p}}$ was constant at pico-farad $(\mathrm{pF})$ level, which suggested $C_{\mathrm{p}}$ had little relationship with the surface modification and the thermal annealing process.

Comparing the IS response of the H-DND with the untreated DND sample, a Warburg component was found in the equivalent circuit in the hydrogen-terminated sample. Zang and Portet et al. proposed similar Warburg components, which were observed in electrochemical experiments on DND powder. ${ }^{25,38}$ The presence of the Warburg component can be explained by: (1) the porous structure and the surface roughness; (2) the infinite-element approximation of the material. ${ }^{24,25}$ Both of the proposed mechanisms are feasible in our case. At the temperature range below $100^{\circ} \mathrm{C}$, the aggregated DND can be considered as a porous material with a grain size in the order of micrometers (Fig. 1$).^{7}$ On the other hand, the aggregated DND powder can be considered as a three-dimensional network of individual DND particles in the proposed equivalent circuit model, which is different from single/polycrystalline diamond film. ${ }^{25}$ Surface mutual interactions occur within the three-dimensional network, in association with the presence of $\mathrm{C}-\mathrm{H}$ bonds after the hydrogen plasma treatment.

Chaudhary et al. reported a DND capacitance of $\sim 10 \mathrm{pF}$ at temperatures ranging from $23 \sim 150^{\circ} \mathrm{C}$ and attributed it to a grain boundary contribution. ${ }^{14}$ Bevilacqua et al. studied the impedance response of the untreated DND powder and concluded that a 'grain-interior-like' 
electrical conduction exists below $350^{\circ} \mathrm{C}$. But it was switched to surface-interface conduction at higher temperature. ${ }^{13}$ In our IS measurement of H-DND, there was only single semicircle response observed while the temperature heating up, which indicated only one conduction mechanism occurred during the whole process (Fig. 3. a-f). The average grain size indicates that the effect of small-size and the large surface area-to-volume ratio may reduce the capacitance $C_{\mathrm{p}}$, comparing with the capacitance calculated in single/poly-crystalline diamond films. ${ }^{17-20}$ The hydrogen-termination treatment enhanced the grain boundary conduction on the surface of the DND particles and grain interior effect from the core was undermined. Thus, the GB conduction in the IS plot dominated, whilst little evidence for GI conduction was found. ${ }^{39}$ Hence, we associated that the capacitance with the grain boundaries conduction contribution for H-DND.

During the course of the increasing temperature, two activation energy levels, $E_{\text {act1 }}$ and $E_{\text {act2 }}$, can be calculated from the Arrhenius plot, which suggested two different conduction mechanisms. $E_{\text {act1 }}$ is calculated to be $0.089 \mathrm{eV}$ over the temperature range between $170^{\circ} \mathrm{C}$ and $225^{\circ} \mathrm{C}$. $R_{\mathrm{p}}$ slightly decreases with increasing temperature. I believe that $E_{\mathrm{act} 1}$ is likely to be associated with hydrogen termination. It is known that the hydrogen-termination of diamond thin film can improve the surface conduction and create a negative-electron-affinity (NEA) surface. ${ }^{40}$ Landstrass et al. proposed that the conduction might be caused by the movements of hydrogen and defects from nonactive sites during the annealing process. ${ }^{41}$ Botev et al. presented an activation energy of $0.1 \mathrm{eV}$ from undoped diamond film by charged-based deeplevel transient spectroscopy (Q-DLTS) method. ${ }^{42}$ Mori et al. assumed an existence of surface conductive layer caused by chemical absorption or oxidization. ${ }^{43}$ Therefore, we suggest that $E_{\text {act1 }}$ is originated from surface hydrogen-termination of DNDs .

At temperatures from $250^{\circ} \mathrm{C}$ to $350^{\circ} \mathrm{C}$, the other activation Energy $E_{\text {act2 }}$ is calculated to be $0.63 \mathrm{eV}$. This level of activation is close to the value of $n$-type phosphorous doping in 
diamond film. ${ }^{44}$ However, further XPS analysis showed that there was no significant trace of phosphorous elements (see Sec. III). Various explanations of this activation energy level have been proposed by other researchers. Ye et al. studied the dielectric properties of nanocrystalline diamond film and found an activation energies at $0.67 \mathrm{eV}$. The author assumed that the phenomenon might be the change of the crystal field caused by thermal expansion, or by surface bond concentration of nanosized particles. ${ }^{18}$ Werner and Huang et al. have assigned this effect to the space charge limited current and Poole-Frenkel mechanism for the non-linear electrical response. ${ }^{45,46}$ Here, we associated the activation energy with the crystalline defects, or the surface $s p^{2}$ carbon phase (non-diamond materials), which had been reported in undoped diamond film. ${ }^{47-49}$ For all the Cole-Cole plots, there is only one semicircular response indicating only one conduction mechanism existing for the DND powder. If the chromium impurity contributes to the electrical conduction, there should be a secondary semicircle response in the Cole-Cole plot. In addition, the small concentration of Cr (0.3\%) made it unlikely to form a continuous conduction path within the DND powder. Thus the metallic impurities (Cr) do not contribute to the electrical conduction.

The FTIR and XPS study focused on the thermal stability of the H-DND. In comparison, the CVD diamond film can be oxidized while heating in an oxygen atmosphere over $500^{\circ} \mathrm{C} .^{49}$ Previous reports on diamond powder with a micrometer-range grain size indicated the oxidization temperature was $477^{\circ} \mathrm{C}^{16}$ Zou et al. found that 5-nm DND started to incorporate with the oxygen in air at the $228^{\circ} \mathrm{C}$ by thermogravimetric analysis (TGA) and completely oxidized over $\sim 600^{\circ} \mathrm{C}^{51}$ Based on the FTIR and XPS analysis of DND powder in our research, it is found that oxygen has been incorporated into the DND powder between $100^{\circ} \mathrm{C}$ and $150^{\circ} \mathrm{C}$. At this temperature range, $\mathrm{C}-\mathrm{O}$ bonds formed. $\mathrm{C}=\mathrm{O}$ bonds appeared at the annealing temperature greater than $300^{\circ} \mathrm{C}$ and it also shows a trace of $-\mathrm{COOH}$. Nitrogen can be incorporated into DND powders: (1) during the detonation process, and (2) via the surface 
cyclic carbon lactams $(\mathrm{C}=\mathrm{NH}) .{ }^{9}$ Carbon lactams can be ignored when the temperature is greater than $350^{\circ} \mathrm{C}$. As the annealing temperature increased over $400^{\circ} \mathrm{C}$, the homogeneity of DND powder was enhanced. The FTIR results also revealed that the $\mathrm{C}-\mathrm{H}$ bonds could survive in the environment temperature as high as $400^{\circ} \mathrm{C}$ after hydrogen termination process.

\section{CONCLUSION}

In this paper, the electrical conduction mechanism of H-DND powder was analyzed by impedance spectroscopy and supported by FTIR, as well as XPS analysis. A custom-designed cell was utilized to measure the real-time electrical properties of the H-DND powder at different temperature. The results proved that hydrogen-termination treatment enhanced the electrical conduction and the resistivity reduced four orders of magnitude. The equivalent circuit extracted from the Cole-Cole plot contained a Warburg element, which demonstrated that the H-termination served as a link between the H-DND particles. It also suggests that the main conduction mechanism is on the grain boundary of the H-DND. Arrhenius plot reveals that there are two main conduction principles corresponding to two different activation energy levels, which can be associated to the hydrogen-termination and surface defects outside the DND particles, respectively. As the annealing temperature increased up to $150^{\circ} \mathrm{C}$, the surface oxidization occurred and formed C-O bonds. The carboxyl bonds appeared as the temperature reached $300^{\circ} \mathrm{C}$. The nitrogen incorporation functional group was found on the surface on the DND particles' core, which could be removed after annealing treatment at $350^{\circ} \mathrm{C}$

\section{ACKNOWLEGDEMENTS}

The authors wish to acknowledge the funding for this research provided by the Engineering and Physical Sciences Research Council (EPSRC: EP/H034269/1). The authors 
also acknowledge Mr. Lei Zhou (Birmingham University) for SEM images of DND samples; Prof. J. Sullivan, B. Shi, S. Saied (Midland Surface Analysis Ltd, Aston University) for XPS analysis and Dr. Defang Ouyang (Life \& Health Science School, Aston University) for FTIR experiments. 
TABLE I. Parameters extracted from equivalent circuit

\begin{tabular}{|c|c|c|}
\hline Sample & $C_{\mathrm{p}}(\mathrm{pF})$ & $R_{\mathrm{p}}(\mathrm{M} \Omega)$ \\
\hline Untreated DND & 13.1 & 7000 \\
\hline H-terminated (room temperature) & 12.8 & 0.246 \\
\hline $50^{\circ} \mathrm{C}$ & 17.6 & 5.20 \\
\hline $100^{\circ} \mathrm{C}$ & 17.3 & 47.4 \\
\hline $150^{\circ} \mathrm{C}$ & 18.0 & 149 \\
\hline $200^{\circ} \mathrm{C}$ & 21.8 & 1840 \\
\hline $250^{\circ} \mathrm{C}$ & 21.0 & 2220 \\
\hline $300^{\circ} \mathrm{C}$ & 22.1 & 834 \\
\hline $350^{\circ} \mathrm{C}$ & 22.7 & 246 \\
\hline $400^{\circ} \mathrm{C}$ & 14.9 & 797 \\
\hline
\end{tabular}

TABLE II. XPS analysis and content of impurities on DND

\begin{tabular}{|c|c|c|c|c|}
\hline Sample & $\begin{array}{c}\text { N1s Content } \\
\text { (at.\%) }\end{array}$ & $\begin{array}{c}\text { O1s Content } \\
\text { (at.\%) }\end{array}$ & $\begin{array}{c}\text { C1s Content } \\
\text { (at.\%) }\end{array}$ & $\begin{array}{c}\text { Cr2p Content } \\
\text { (at.\%) }\end{array}$ \\
\hline Untreated & 1.5 & 4.2 & 94.0 & 0.3 \\
\hline H-terminated & 2.6 & 1.6 & 95.5 & 0.3 \\
\hline $50^{\circ} \mathrm{C}$ & 1.6 & 1.7 & 96.3 & 0.4 \\
\hline $100^{\circ} \mathrm{C}$ & 1.6 & 2.0 & 96.1 & 0.3 \\
\hline $150^{\circ} \mathrm{C}$ & 1.6 & 1.9 & 96.2 & 0.3 \\
\hline $200^{\circ} \mathrm{C}$ & 1.8 & 2.5 & 95.4 & 0.3 \\
\hline $250^{\circ} \mathrm{C}$ & 2.0 & 3.3 & 94.4 & 0.3 \\
\hline $300^{\circ} \mathrm{C}$ & 2.0 & 5.3 & 92.3 & 0.4 \\
\hline $350^{\circ} \mathrm{C}$ & 2.0 & 4.9 & 92.8 & 0.3 \\
\hline $400^{\circ} \mathrm{C}$ & 1.7 & 5.0 & 93.0 & 0.3 \\
\hline
\end{tabular}




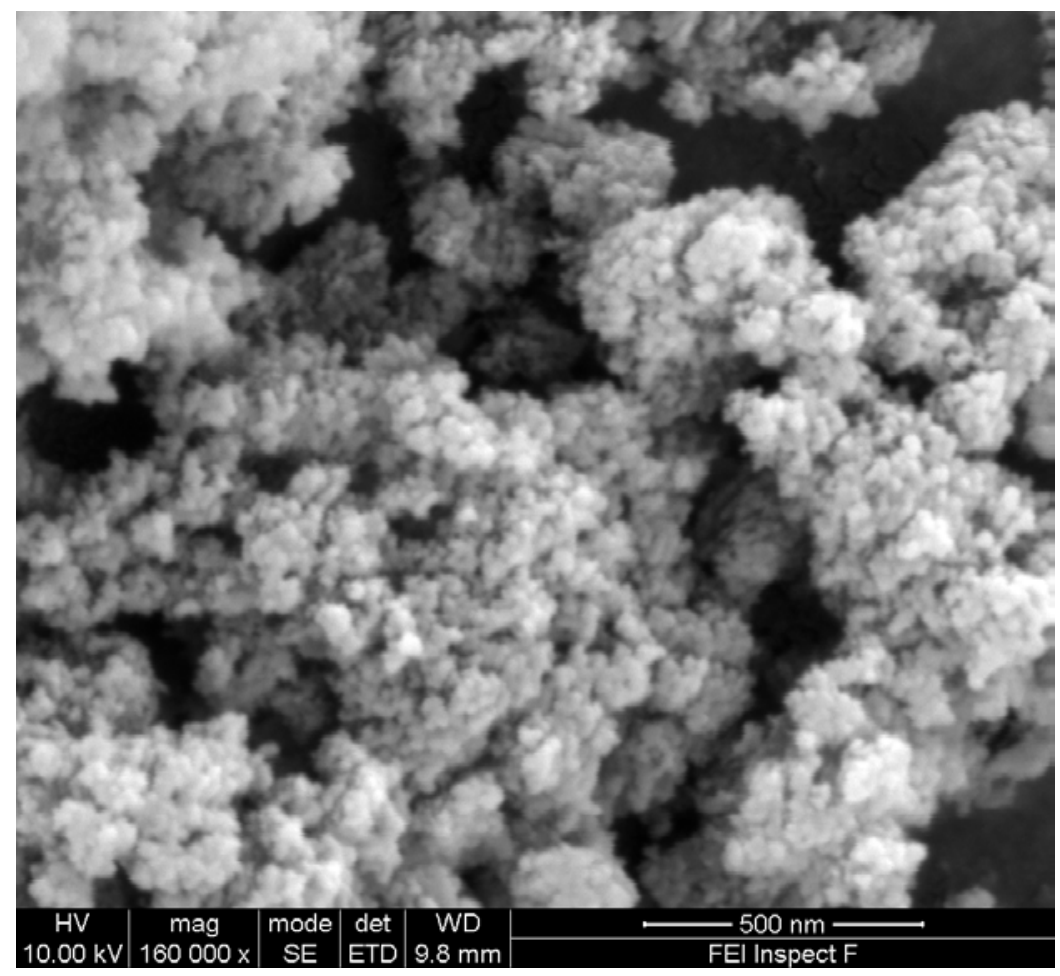

FIG. 1 SEM image of 4 6 nm 97\% untreated nanodiamond (SIGMA-Aldrich Ltd.).

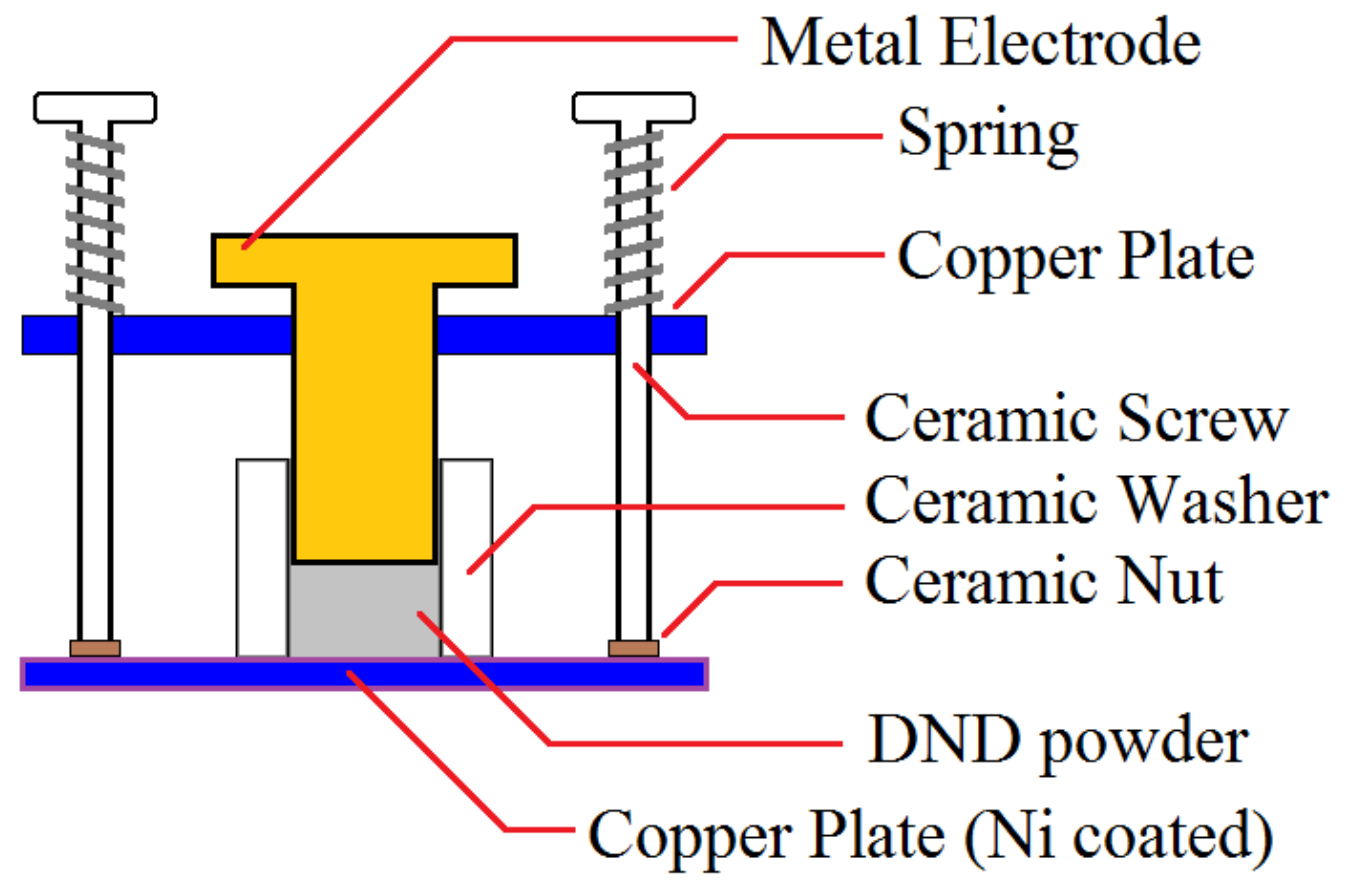

FIG. 2 Cross-section view of the testing cell structure. 

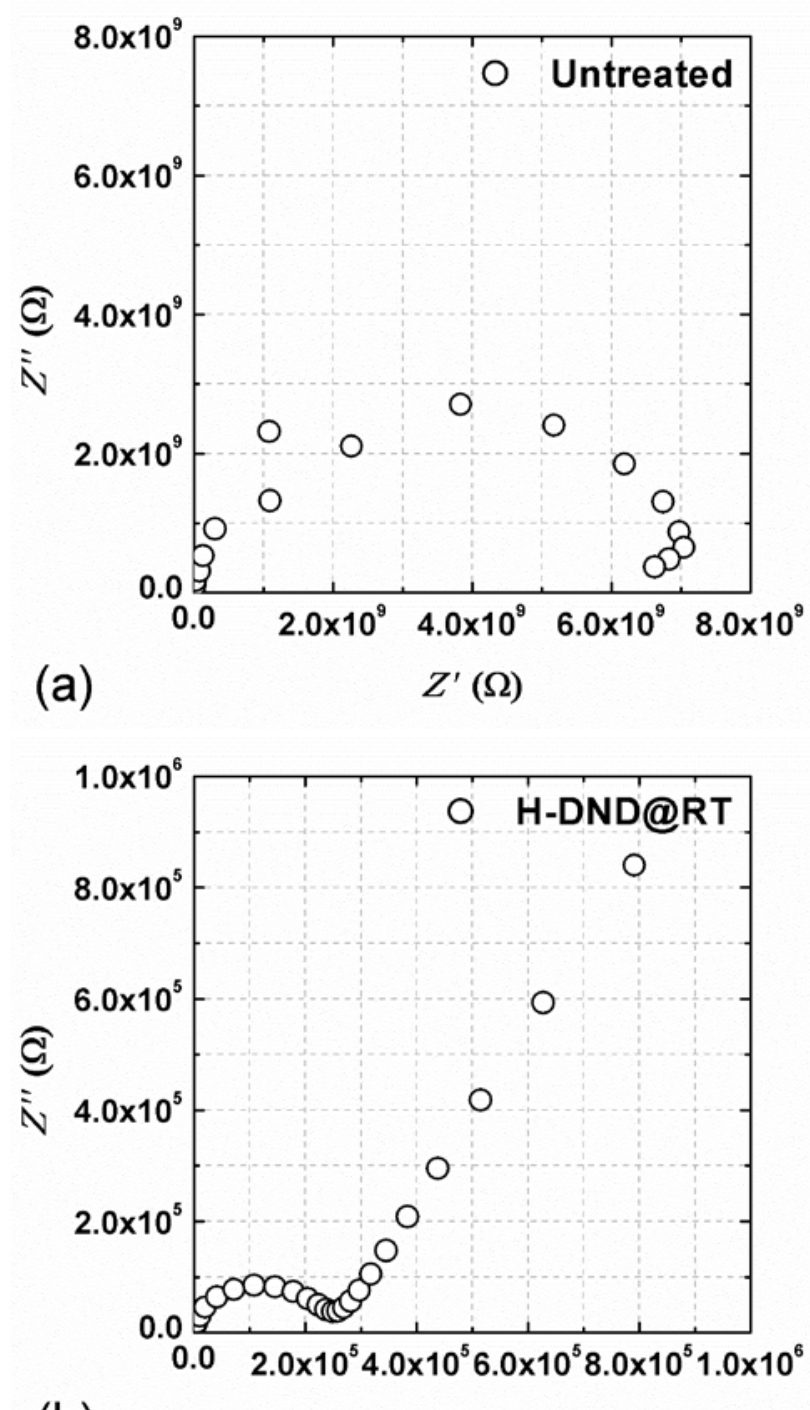

(b)

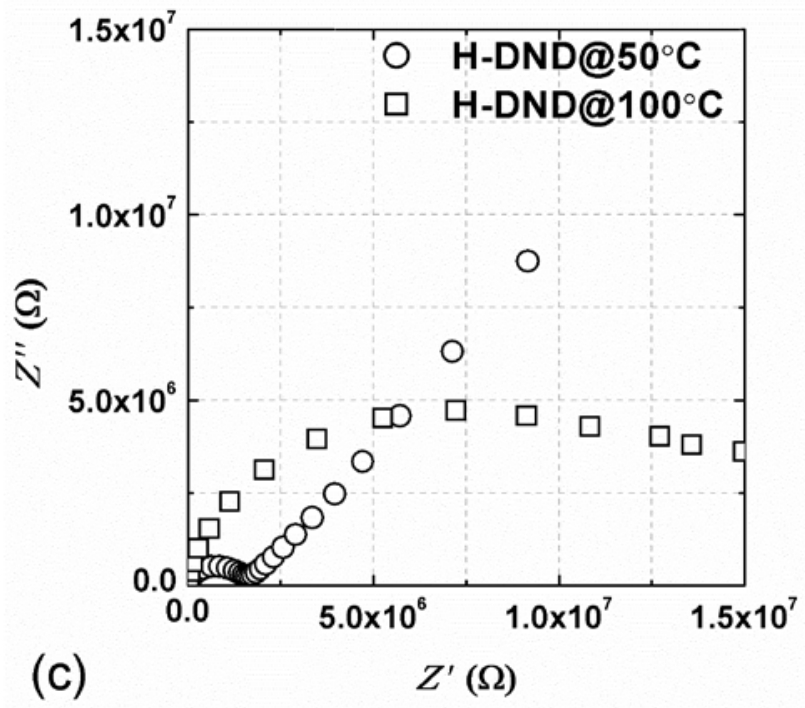



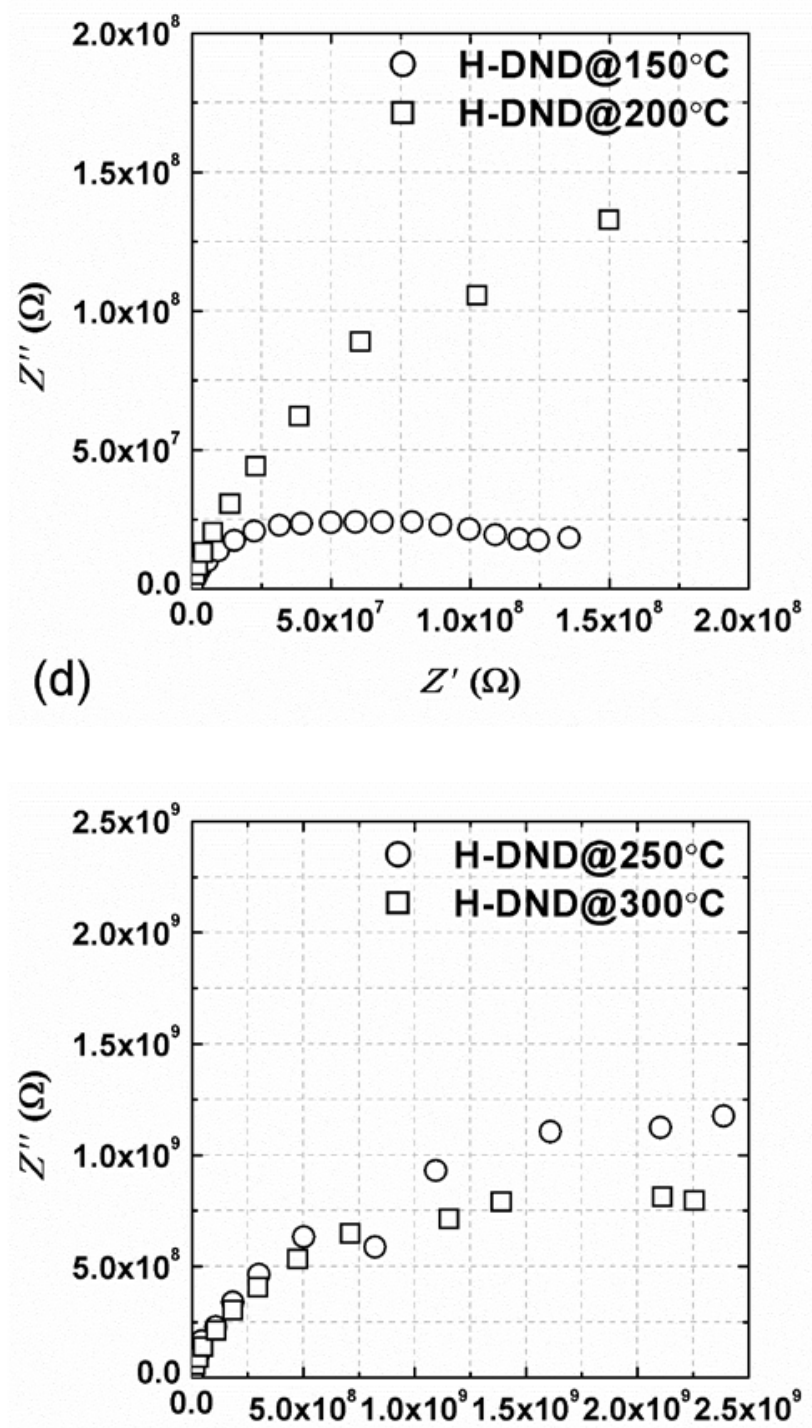

(e)

$Z^{\prime}(\Omega)$

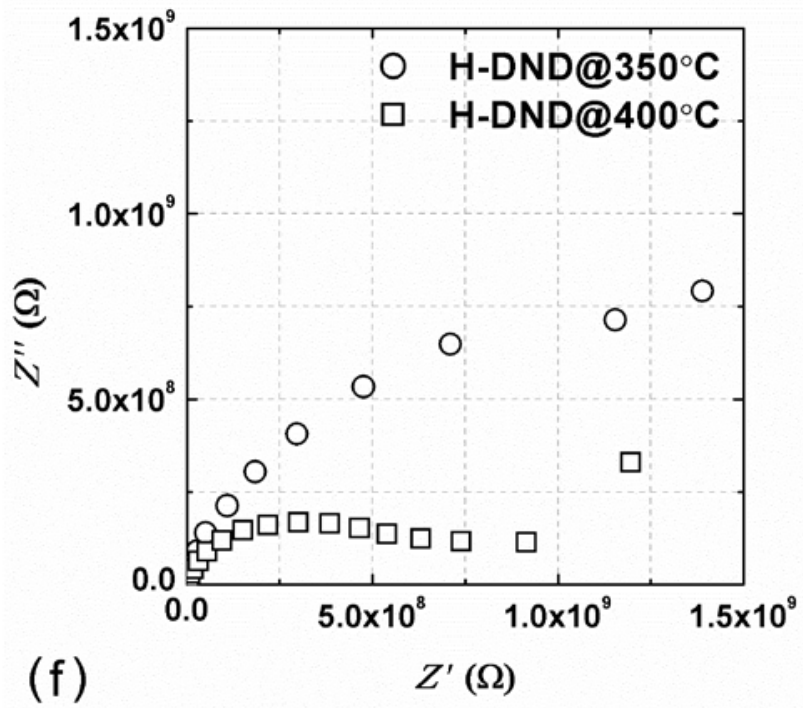


FIG. 3 Impedance spectroscopy of (a) untreated DND; (b) H-terminated DND at room temperature; (c) $\mathrm{H}$-DND annealed at $50^{\circ} \mathrm{C}$ and $100^{\circ} \mathrm{C}$; (d) $\mathrm{H}$-DND annealed at $150^{\circ} \mathrm{C}$ and $200^{\circ} \mathrm{C}$; (e) $\mathrm{H}-\mathrm{DND}$ annealed at $250^{\circ} \mathrm{C}$ and $300^{\circ} \mathrm{C}$; (f) $\mathrm{H}-\mathrm{DND}$ annealed at $350^{\circ} \mathrm{C}$ and $400^{\circ} \mathrm{C}$.

(a) Untreated DND
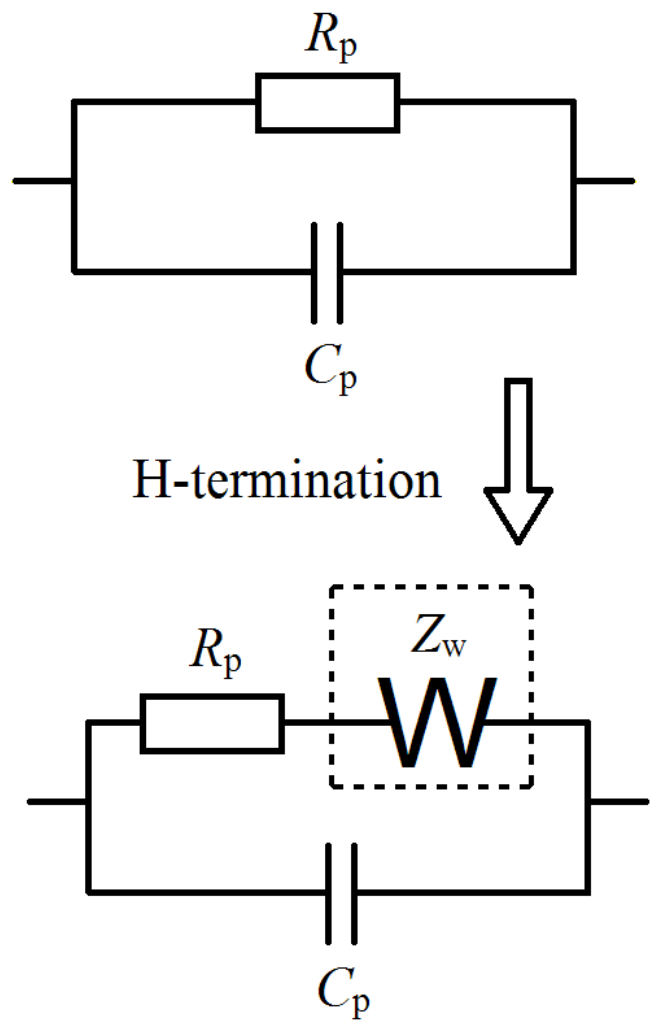

(b) H-terminated DND

(with Warburg element)

FIG. 4 Equivalent circuit extracted from Cole-Cole plot before/after H-termination treatment. 


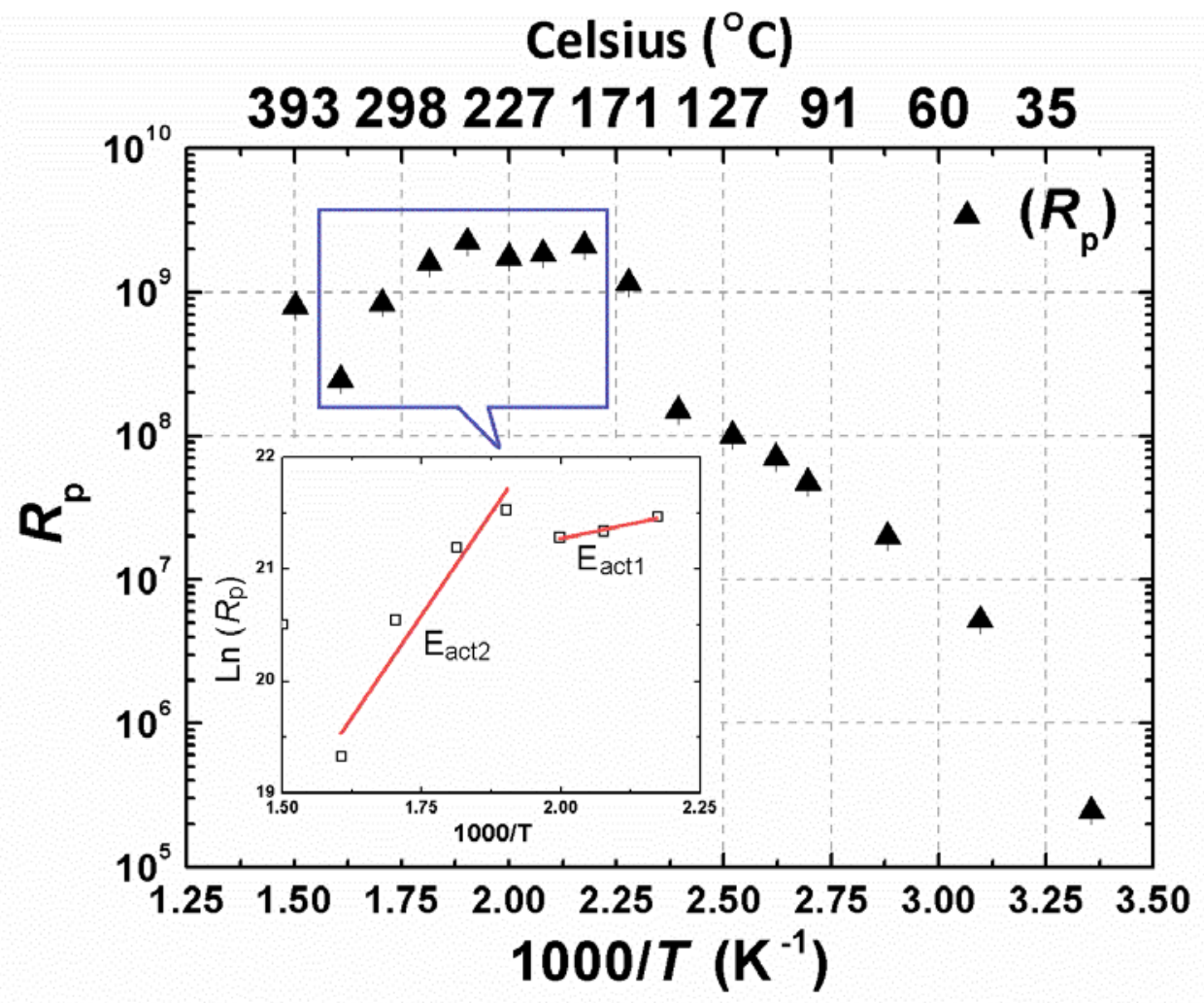

FIG. 5 Arrhenius relationship of resistance $R_{p}$ extracted from the Cole-Cole plots.

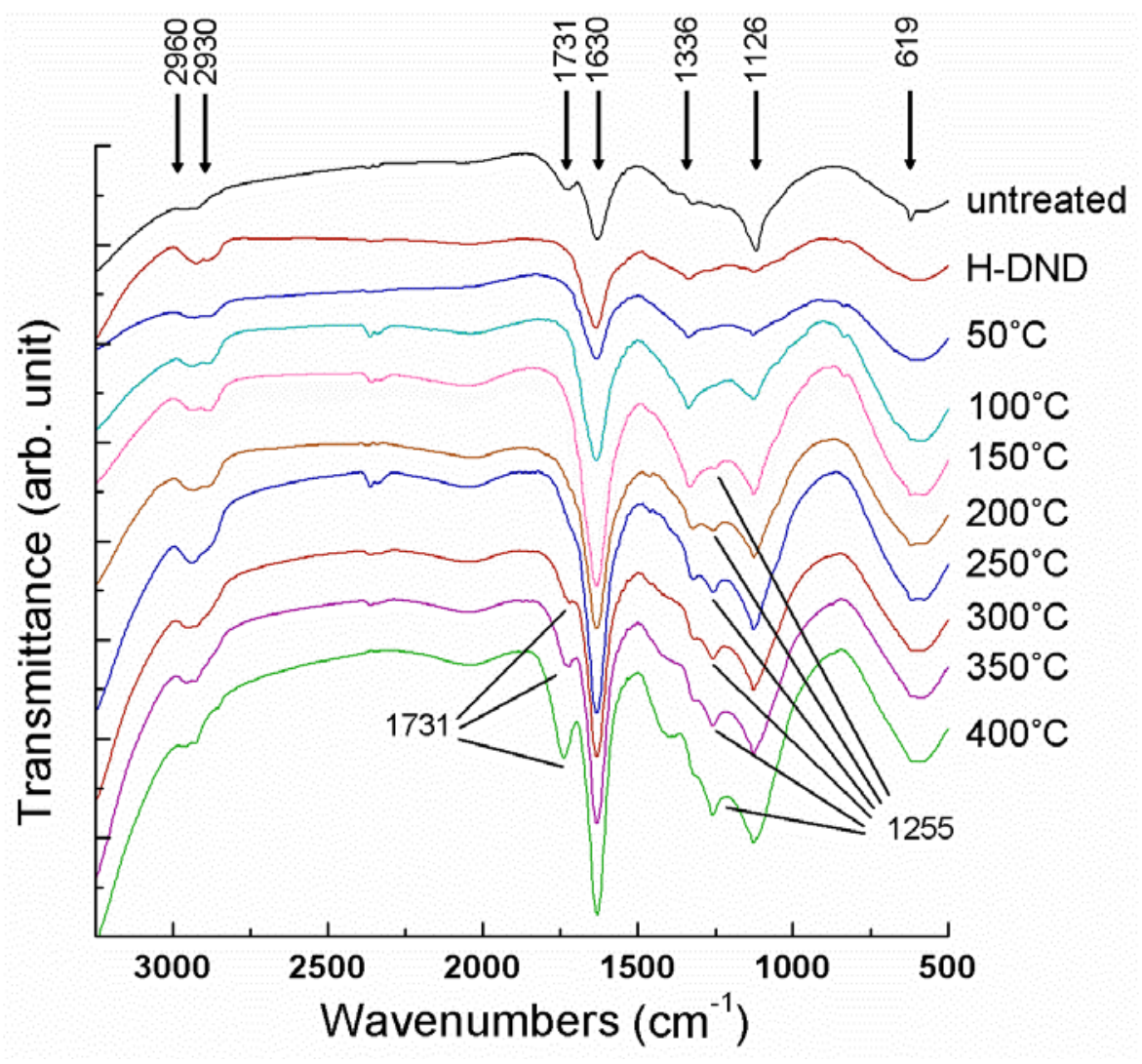


FIG. 6 FTIR analysis of untreated DND, hydrogen-passivated DND and H-DND annealed from $50^{\circ} \mathrm{C} \sim 400^{\circ} \mathrm{C}$. All the DND powder was performed thermal treatment in air and then pressed into $\mathrm{KBr}$ pellets.

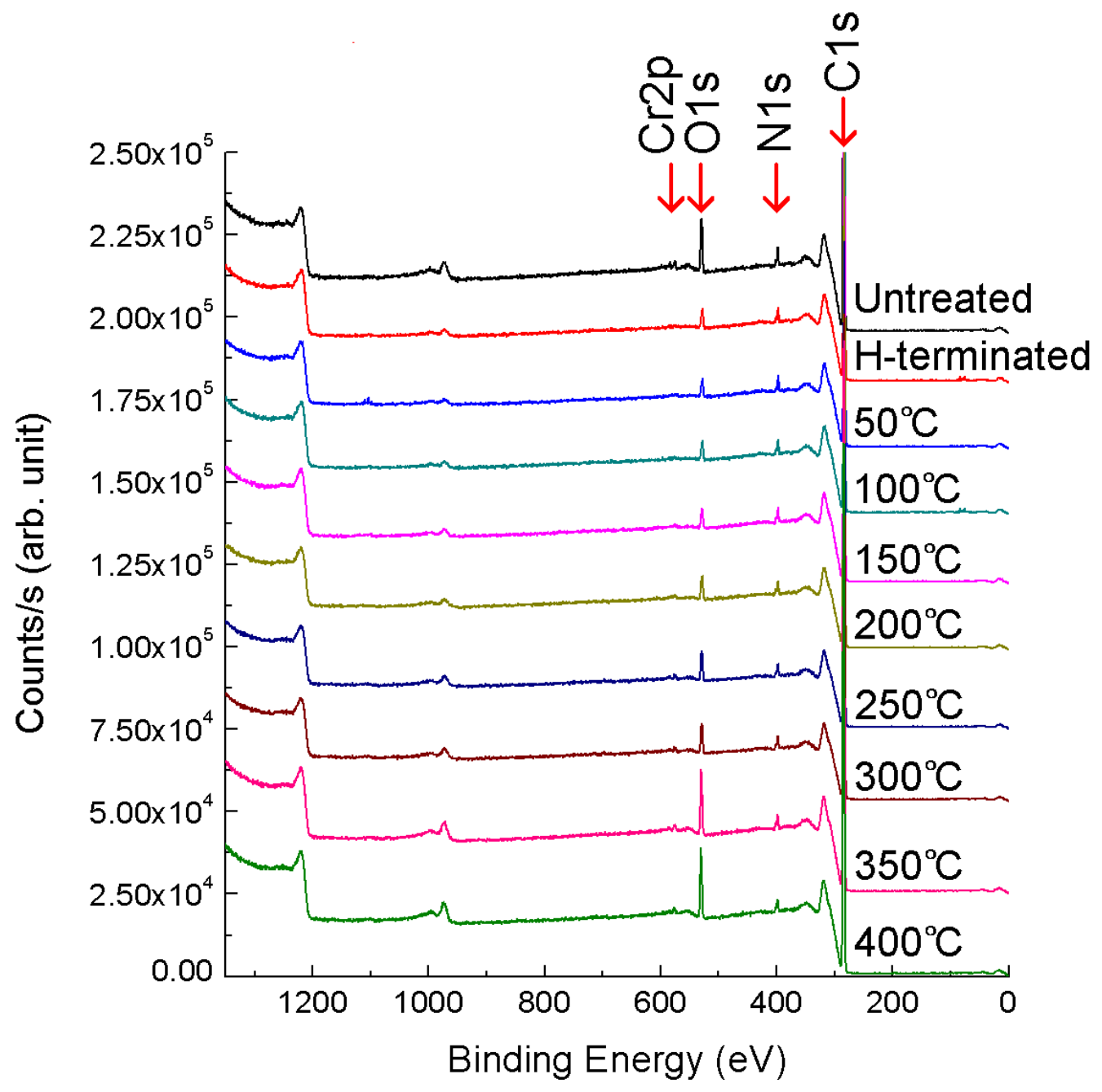

FIG. 7 XPS Survey spectra of untreated, H-terminated and $400^{\circ} \mathrm{C}$ annealed DND samples. The top of the significant $\mathrm{C} 1 \mathrm{~s}$ peak has been cut off in order to highlight the other impurities. 


\section{Reference}

1. M. Chen, E. D. Pierstorff, R. Lam, S. Y. Li, H. Huang, E. Osawa, and D. Ho, ACS Nano 3 (7), 2016 (2009).

2. G. P. Bogatyreva, M. A. Marinich, E. V. Ishchenko, V. L. Gvyazdovskaya, G. A. Bazalii, and N. A. Oleinik, Phys. Sol. Stat. 46 (4), 738 (2004).

3. C. C. Fu, H. Y. Lee, K. Chen, T. S. Lim, H. Y. Wu, P. K. Lin, P. K. Wei, P. H. Tsao, H. C. Chang, and W. Fann, P. Natl. Acad. Sci. USA 104 (3), 727 (2007).

4. V. S. Bondar', I. O. Pozdnyakova, and A. P. Puzyr', Phys. Sol. Stat. 46 (4), 758 (2004).

5. T. S. Huang, Y. Tzeng, Y. K. Liu, Y. K. Chen, K. R. Walker, R. Guntupalli, and C. Liu, Diamond. Relat. Mater. 13 (4-8), 1098 (2004).

6. X. Cui, X. Liu, A. S. Tatton, S. P. Brown, H. Ye and A. Marsh, Appl. Mater. Interface 4 (6), 3225-3232 (2012).

7. Ultrananocrystalline diamond: Synthesis, Properties, and Applications, William Andrew, edited by O. A. Shenderova and D. M. Gruen (2007).

8. R. Hoffmann, A. Kriele, H. Obloh, J. Hees, M. Wolfer, W. Smirnov, N. Yang, and C. E. Nebel, Appl. Phys. Lett. 97, 052103 (2010).

9. T. Jiang and K. Xu, Carbon 33 (12), 1663 (1995).

10. M. Yeganeh, P. R. Coxon, A. C. Brieva, V. R. Dhanak, L. Siller, and Y. V. Butenko, Phys. Rev. B 75, 15 (2007).

11. S. Zeppilli, J. C. Arnault, C. Gesset, P. Bergonzo, and R. Polini, Diamond. Relat. Mater. 19 (7-9), 846 (2010).

12. F. Y. Xie, W. G. Xie, L. Gong, W. H. Zhang, S. H. Chen, Q. Z. Zhang, and J. Chen, Surf. Interface Anal. 42 (9), 1514 (2010).

13. M. Bevilacqua, S. Patel, A. Chaudhary, H. T. Ye, and R. B. Jackman, Appl. Phys. Lett. 93, 13 (2008). 
14. A. Chaudhary, J. O. Welch, and R. B. Jackman, Appl. Phys. Lett. 96, 123115 (2010).

15. S. Su, J. L. Li, V. Kundrát, A. M. Abbot, and H. Ye, Diamond. Relat. Mater. 24, 49-53 (2011).

16. K. Tankala, T. Debroy, M. Alam, J. Mater. Res. 5, 2483 (1990).

17. H. Ye, O. A. Williams, R. B. Jackman, R. Rudkin, and A. Atkinson, Phys. Stat. Sol. A 193 (3), 462 (2002).

18. H. T. Ye, R. B. Jackman, and P. Hing, J. Appl. Phys. 94 (12), 7878 (2003).

19. H. T. Ye, C. Q. Sun, H. T. Huang, and P. Hing, Appl. Phys. Lett. 78 (13), 1826 (2001).

20. H. T. Ye, O. Gaudin, R. B. Jackman, P. Muret, and E. Gheeraert, Phys. Stat. Sol. A 199 (1), 92 (2003).

21. N. Tumilty, J. Welch, H. Ye, R. S. Balmer, C. Wort, R. Lang, and R. B. Jackman, Appl. Phys. Lett. 94, 052107 (2009).

22. Fast Ion Transport in Solids, ELESVIER, edited by M. Kleitz, J. H. Kennedy, P. Vashishta, J. N. Mundy, and G. K. Shenoy, (1979).

23. Impedance Spectroscopy Theory, Experiment, and Applications, WIELYINTERSCIENCE, edited by E. Barsoukov, and J. R. Macdonald, (1992).

24. N. Gibson, O. Shenderova, T. J. M. Luo, S. Moseenkov, V. Bondar, A. Puzyr, K. Purtov, Z. Fitzgerald, and D. W. Brenner, Diamond. Relat. Mater. 18 (4), 620 (2009).

25. J. B. Zang, Y. H. Wang, S. Z. Zhao, L. Y. Bian, and J. Liu, Diamond. Relat. Mater. 16, 16 (2007).

26. V. Pichot, M. Comet, E. Fousson, C. Baras, A. Senger, F. Le Normand, D. Spitzer, Diamond. Relat. Mater. 17 (1), 13 (2008).

27. Q. Zou, Y. G. Li, L. H. Zou, and M. Z. Wang, Mater. Char. 60, 1257 (2009).

28. S. Osswald, G. Yushin, V. Mochalin, S. O. Kucheyev, Y. Gogotsi, J. Am. Chem. Soc. 128, 11635 (2006). 
29. P. -H, Chung, E. Perevedentseva, J. -S, Tu, C. C. Chang, C. -L, Cheng, Diamond. Relat. Mater. 15, 622 (2006).

30. Y. Kaibara, K. Sugata, M. Tachiki, H. Umezawa, H. Kawarada, Diamond. Relat. Mater. 12, 560 (2003).

31. A. M. Schrand, S. A. Ciftan Hens, O. A. Shenderova, Sol. Stat. Mater. Sci. 34:18-74 (2009).

32. A. Dementjev, K. Maslakov, I. Kulakova, V.Korolkov, and V. Dolmatov, Diamond. Relat. Mater. 16, 2083-2086 (2007).

33. V. N. Mochalin, O. Shenderova, D. Ho, and Y. Gogotsi, Nature Nanotech. 2091 (2011).

34. V. Pichot, M. Comet, E. Fousson, C. Baras, A. Senger, F. Le Normand, and D. Spitzer, Diamond Relat. Mater. 17 13-22 (2008).

35. M. Yeganeh, P. R. Coxon, A. C. Brieva, V. R. Dhanak, L. Šiller, Yu. V. Butenko, Phys. Rev. B. 75, 155404 (2007).

36. Y. Hu, O. A. Shenderova, Z. Hu, C. W. Padgett, D. W. Brenner, Carbon nanostructures for advanced composites, Rep. Prog. Phys. 69, 1847 (2006).

37. M. Bevilacqua, A. Chaudhary, and R. B. Jackman, J. Appl. Phys. 106, 123704 (2009).

38. C. Portet, G. Yushin, and Y. Gogotsi, Carbon 45, 2511 (2007).

39. M. Bevilacqua, N. Tumitty, C. Mitra, H. Ye, T. Feygelson. J. E. Butler and J. B. Jackman, J. Appl. Phys. 107, 033716 (2010).

40. C. E. Nebel, C. Sauerer, F. Ertl, M. Stutzmann, C. F. O. Graeff, P. Bergonzo, O. A. Williams, and R. B. Jackman, Appl. Phys. Lett. 79, 45411 (2001).

41. M. I. Landstrass, and K. V. Ravi, Appl. Phys. Lett. 55, 1391 (1989).

42. A. A. Botev, L. L. Bouilov, B. V. Spitsyn, G. A. Sokolina, V. I. Polyakov, O. N. Ermakova, et al. $3^{\text {rd }}$ Int. Symp. on Diamond Materials 998-1003 (1993). 
43. Y. Mori, N. Eimori, A. Hatta, T. Ito, and A. Hiraki, Jpn. J. Appl. Phys. Part 2 31, L1718 (1992).

44. S. Curat, H. Ye, O. Gaudin, and R. B. Jackman, J. Appl. Phys. 98, 073701 (2005).

45. M. Werner, O. Dorsch, A. Hinze, E. Obermeier, R. E. Harper, C. Johnston, P. R. Chalker, and I. M. Buckley-Golder, Diamond. Relat. Mater. 2, 825 (1993).

46. B. Huang, and D. K. Reinhard, Appl. Phys. Lett. 59, 1494 (1991).

47. Y. Muto, T. Sugino, K. Kobashi, and J. Shirafuji, Jpn. J. Appl. Phys. L4, 31 (1992).

48. T. Sugino, Y. Muto, K. Karasutani, J. Shirafuji, and K. Kobashi, Diamond Relat. Mater. 2, 803 (1993).

49. J. Mort, M. A. Machonkin, and K. Okumura, Appl. Phys. Lett. 59, 455 (1991).

50. C. Sun, H. Xie, W. Zhang, H. Ye, P. Hing, J. Phys. D: Appl. Phys. 33, 2196 (2000).

51. Q. Zou, M. Z. Wang, Y. G. Li, L. H. Zou, H. Yu, Y. C. Zhao, Micro \& Nano Lett. 4, 133 (2009). 